\title{
Pavement Materials Characterization of Hot-Mix Asphalt Mixes in Western Australia
}

\author{
Ainalem Nega ${ }^{1,}$,, Hamid Nikraz ${ }^{2, b}$, Colin Leek $^{3, \mathrm{c}}$ and Behzad Ghadimi ${ }^{4, \mathrm{~d}}$ \\ ${ }^{1}$ PhD Candidate, Department of Civil Engineering, Curtin University, GPO Box U1987, Perth, WA 6845, Australia \\ ${ }^{2}$ Professor, Head of Department of Civil Engineering, Curtin University, GPO Box U1987, Perth, WA 6845, Australia \\ ${ }^{3}$ Adjunct Professor, Department of Civil Engineering, Curtin University, GPO Box U1987, Perth, WA 6845, Australia \\ ${ }^{4}$ PhD Candidate, Department of Civil Engineering, Curtin University, GPO Box U1987, Perth, WA 6845, Australia \\ a Ainalem.Nega@ curtin.edu.au, ${ }^{\text {b }} \underline{\text { H.Nikraz@ } @ \text { curtin.edu.au, }}{ }^{\mathrm{c}}$ C.Leek@curtin.edu.au, \\ ${ }^{\mathrm{d} B e h z a d . G h a d i m i @ \text { postgrad.curtin.edu.au }}$
}

\begin{abstract}
The use of deep strength asphalt materials characterization to construct and restore the heavily urban roads where damage has been induced is rapidly grown in Western Australia. Five different types of asphalt mixes were produced in laboratory to modify pavement performance mixture. The main role of this research is to evaluate the pavement materials characterization for Western Australia road. In this study, laboratory test for tensile strength, resilient modulus, wheel tracking, binder contents, Marshall Compaction, and air voids contents test were taken to analyze each asphalt mixtures. The results indicated that AC20-75 and AC14-75 asphalt mixes blow were in a good pavement performance as compared to other asphalt mixes. For a mix design purposed, all the asphalt mixes that are used in this study can strength and stable the stiffness of pavement that is notable, and the modification effect rank can be described as AC20-75 Blow > AC14-75 Blow > AC14-50 Blow > AC7-50 Blow > SMA7-50 Blow in this research.
\end{abstract}

Author keywords: Asphalt mixture; air voids contents; binders contents; Marshall compaction; materials characterization; resilient modulus; tensile strength; wheel tracking; Western Australia

\section{Introduction}

The use of full depth asphalt pavements to construct and rehabilitate heavily loaded urban roads has rapidly grown in Western Australia (WA) over the past 4 years. There is limited data available from testing carried out by the Mainroads about the characteristics and variability of WA asphalt mixes. Although some data is available from testing carried out by others on Mainroads contracts, but it also would be necessary to determine whether Mainroads WA owns this data and has the right to publish the data so that it can be used to predict the likely performance of WA full depth asphalt pavements.

High demand for new asphalt pavement often requires that paving be done unfavourable construction conditions. For example, Low air temperatures, high winds, and night construction create adverse conditions for hot-mix asphalt paving [1]. This presents a risk for road owners and contractors. To achieve optimum load-bearing and weathering characteristics, an asphalt mix must be compacted to a specific range of density, and the time required for hot-mix asphalt to reach the proper compaction temperature to achieve this density decreases with an increased rate of cooling [1].

Hot-mix asphalt (HMA) is known by many different names: asphaltic concrete, plant mix, bituminous mix, bituminous concrete, and many others $[2,3]$. It is a combination of two primary ingredients - aggregates and asphalt binder. About $95 \%$ of the total mixtures by weight are aggregates, and these are mixed with an approximately 5\% of asphalt binder to produce HMA [2, 3]. Hot and cold asphalt mixes are comprised of two major materials: aggregates (mixture of sand, gravel, crushed stone, slag and mineral filler) and asphalt cement (crude oil, hydrated lime and dust) as discussed on literature by [4-8]. Bitumen had been defined by various sources as crude oil with a dynamic viscosity at reservoir conditions more than 10,000 centipoise [4, 9-13]. 
The asphalt concrete or hot mix asphalt (HMA) is the most widely used infrastructure materials for road construction. Hot mix asphalts can be described as a multiphase heterogeneous material composed of a viscoelastic asphalt binder, irregular rigid aggregate particle in high volume fraction, and small percentage of air voids [14]. These various properties of materials component contribute to the complex mechanical behavior of HMA, which can be characterized as viscoelasticity, and plastic under different condition such as temperature, load application and aging $[14,15]$. Thus the mechanical behavior of hot mix asphalt should be understood by not only the individual properties of HMA components, but also by considering asphalt binder and aggregate acting together.

The goal of this study is to evaluate the pavement materials characteristics of hot-mix asphalt for Western Australia roads using a laboratory tests so that data can be used to predict the likely performance of Western Australia flexible pavement.

\section{Materials and Methods}

\subsection{Materials}

Types of hot mixed asphalt used on the Mainroads Western Australia network are dense graded asphalt (DGA), open graded asphalt (OGA) and stone mastic asphalt (SMA). DGA, the most common type of asphalt, provides optimal structure strength and generally good resistance to deformation. OGA is designed to drain water through the asphalt to remove excess water from the tyre/road surface. SMA is similar to OGA but has a high proportion of dust and high binder contents to achieve an improved fatigue life. SMA has a texture surface but does not drain water through its layer as does OGA [4, 16, 17]. All Materials selected for this project were from local sources and are indigenous of Western Australian pavement materials used in the industry.

\subsection{Methods}

The design method specified by Mainroads Western Australia is the Marshall method of mix design. The aim of the method is to satisfy specified design criteria. The descriptions of asphalt mixes design are as following:

- SMA7-50 blow: thickness of $7 \mathrm{~mm}$ granite stone mastic asphalt (SMA)

- AC7-50 blow: thickness of $7 \mathrm{~mm}$ open graded granite

- AC14-50 blow: thickness of $14 \mathrm{~mm}$ dense graded granite (intersection mix)

- AC14-75 blow: thickness of $14 \mathrm{~mm}$ dense graded granite (intermediate mix)

- AC20-75 blow: thickness of $20 \mathrm{~mm}$ dense graded granite (intermediate mix)

In order to assess the pavement material characterization of hot-mix asphalt mixes, it was necessary to obtain laboratory data. During an individual asphalt mixes run, specimen was taken and assessed in different categories of asphalt mixes. Specimens were subjected to the following laboratory characterization tests:

- Tensile strength ratio (TSR) test

- Resilient modulus test

- Wheel tracking test

- Asphalt binder content test

- Marshall Stability test

- Air voids content test

After samples had cooled to room temperature, bulk density and maximum specific gravity were performed according to the Australian Standard Test Method, AS 2891. Three specimens to each asphalt mixes were tested as per AS 2891, AG PT/231 and AG PT/23 [18-20]. Air voids were calculated using bulk specific gravity and maximum theoretical specific gravity data. Specimens were placed in a water bath at $60^{\circ} \mathrm{C}$ for a period of $30 \mathrm{~min}$ and were tested for Marshall Stability 
and flow. The details methods of sampling and testing of hot-mix asphalt in Australian Standard Testing Method are shown in Table 1.

Table 1: Methods of Sampling and Testing Asphalt in Australian Standard Test Method [18-20]

\begin{tabular}{|c|c|}
\hline Material Test & Test Method \\
\hline Tensile strength ratio & AGPT/T232 \\
\hline Resilient modulus & AS 2891.13.1 \\
\hline Wheel tracking & AGPT/T231 \\
\hline Asphalt binder content & AS 2891.1.1 \\
\hline Marshall compaction & AS 2891.9.3 \\
\hline Air voids content & AS 2891.9.2 \\
\hline
\end{tabular}

\section{Pavement Materials Characterization of Asphalt Mixes}

\subsubsection{Tensile strength ratio (TSR)}

The conflict between bitumen, water and aggregate affinities has been an issue since the inception of asphalt as a paving material. In many situations the issue is minor, but when it does manifest as a stripping failure, the results can be catastrophic [20]. Moisture sensitivity relate to the potential for loss adhesion between the binders and aggregate in the presence of moisture. This of adhesion is commonly referred to as stripping potential of asphalt- tensile strength ratio (TSR) [19, 20]. Stripping in asphalt is a complex mechanism. Where stripping occurs, it is often a combination of more than one such as climate and traffic, asphalt mix permeability, class of binder, poor coats of aggregate due to presence of clay or dust contamination, affinity of bitumen and asphalt mix design including type of tiller and use of other additives.

\subsubsection{Resilient modulus}

The resilient modulus is defined as a ratio of the deviator stress to the recoverable strain. It is known that the bituminous material is not elastic, but it experiences some permanent deformation after each load application [21]. However, if the load is small compared to the strength of material and is reported for number of times, the deformation under each load repetition is nearly completely recoverable and proportional to the load can be considered being elastic [22]. Resilient modulus is a measure of material's deflection behavior where a pavement life and surface deflection are strongly related [23]. It is also a fundamental and rational material property that needs to be includes in pavement design.

\subsubsection{Wheel tracking}

Australia initially adopted the dynamic creep test as the preferred method of determining the rut resistance of asphalt mixtures [20]. Currently, wheel tracking is selected as the most suitable test method for measuring the rut resistance of asphalt mixtures [20, 24]. The wheel tracking test consists of a loaded wheel assembly and a confined mould in which a $300 \times 300 \times 200 \mathrm{~mm}$ specimen of asphalt mix is rigidly restrained on its four sides. A motor and a reciprocating device provide the forward and backward motion to the wheel at the rate of 24 passes per minute along the length of the slab. The temperature during the test is maintained by a water bath over and around the mould.

\subsubsection{Binder contents}

The combined effect of binder content and air voids in a mix in the form of percent voids filled binder (VFB) has also been considered as an useful parameter in the fatigue life predication models [25, 26, SHRP27]. Santucci [28] applied a correction factor to estimate the fatigue lives of mixes with binder and air void contents other than the mixes with $\mathrm{V}_{\mathrm{b}}=11 \%$ and $\mathrm{V}_{\mathrm{a}}=5 \%$, evaluated controlled stress fatigue tests. 


\subsubsection{Marshall compaction}

Recent laboratory studies have shown that the compaction can highly affect the performance of the hot-mix asphalt (HMA) and stone mastic asphalt (SMA) mixtures [29, 30]. Inappropriate compaction may draw the binder to the surface of HMA and SMA causing flushing of the surface and loss of texture or aggregate segregation [31]. California kneading compactor, Gyratory compactor and Marshall Hammer are being used as SMA compactors due to mix design method [29].

\subsubsection{Air voids contents}

The air voids content in a mix is a function of void in mineral aggregate (VMA), binder content and level of compaction. The air voids (AV) content of a mix can affect the stability of durability of asphalt pavement. Asphalt mixes should be designed to have the lowest practical air voids value so that it can be reduce the aging of the binder, water penetration and stripping of binder from the aggregate. If the air void content asphalt in service is too less (less than 2 or 3\%), plastic flow may occur resulting in flushing, bleeding, shoving and rutting of the pavement [19].

Choubane, Page and Musselman [32] described that the air void content of an asphalt mixture is an important factor that affect the performance of the pavement throughout its service life. High air voids in a finished pavement, particularly if the voids are connected, will adversely affect its stability and durability of asphalt pavement performance in various ways such as air filtration into a permeability pavement can accelerates the aging and lead to potential pavement distresses. The permeability of a pavement is generally assumed to be proportional to its air void content. However, the lack of void interconnection and size dimension of the individual void may result in a watertight pavement of relatively increase AV content.

\section{Results and Analysis}

A summary of average tensile strength ratio of dry and moisture condition is shown in Table 2 . From the data presented, it can be seen that the AC7-50 blow asphalt mix has generally had high TSR of $112.9 \%$ as compared to other asphalt mixes. AC20-75 blow was the second best to have nearly reached a TSR of AC7-50 blow. This showed that the asphalt mixes are non-moisture susceptible. SMA7-50, AC14-50 and AC14-75 blow asphalt mixes had also relatively low as compared to AC7-50 and AC20-75 blow asphalt mixes but both of them are not susceptible to moisture. According to AASHTO T283,"'Resistance of Compacted Bituminous Mixture to Moisture Induced Damage", the design asphalt mixture is judged to be non-moisture susceptible if it has a TSR greater than 80 percent [33-35].

The average resilient modulus for different types of asphalt mixes is given in Figure 1. As it can be seen from the results, AC20-75 blow asphalt mix had high resilient modulus of $6824 \mathrm{MPa}$ as compared to the other asphalt mixes. AC14-75 blow was the second in rank with $5722 \mathrm{MPa}$. This shows that the asphalt mixes are more stable and durable than the other asphalt mixes in pavement performance. However, SMA7-50, AC7-50 and AC14-50 blow asphalt mix had poor resilient modulus of 2983, 4619, and $4282 \mathrm{MPa}$, respectively. And none of these asphalt mixes tested exceeded the Australian standard limit of $5500 \mathrm{MPa}$. Mainroads Western Australia [36] and Austroad [20] stated that the indirect tensile test asphalt modulus used must exceed $5500 \mathrm{MPa}$. Hicks and Monismith [37] stated that the resilient modulus of partially crushed aggregate decreased with an increase in fine contents, while the modulus increased for crushed aggregate with increasing in fine content. Test temperature (Figure 1), the total recovered strain and $10 \%$ to $90 \%$ rise time (Figure 2) are similar for each asphalt mixes. This showed that the resilient modulus test is based on the determination of Australian Standard. Austroads [20] described a standard that requires a total horizontal strain of 30 to 70 micro strain $(\mathrm{ms})$ has to achieve in sample results if test is used to evaluate the resilient modulus of asphalt mixes. 
The average wheel tracking test for different types of asphalt mixes is shown in Figure 3. The analyses indicated that AC20-75 blow asphalt mix had low rut depth of $1.9 \mathrm{~mm}$ as compared to other asphalt mixes. AC14-75 blow was the second in rank with a rut depth of $2.4 \mathrm{~mm}$. This showed that these asphalt mixes are high rut resistance of asphalt mixture and less to pavement distress and asphalt fatigue cracking. However, the rut depth observed for SMA7-50 blow was $15 \mathrm{~mm}$ after 8, 452 cycles while $5 \mathrm{~mm}$ and $4.2 \mathrm{~mm}$ for AC7-50 blow and AC14-50 blow after 10,000 cycles, respectively. This indicated that SMA7-50 blow asphalt mix has high pavement distress and low rut resistance of asphalt mixture. There was also a sudden steep change in slope after 8,000 cycles for SMA7-50 blow. This may be attributed to the stripping of aggregate. No stripping was however, observed after 10, 000 cycles to other asphalt mixes.

A summary of asphalt binder content for different types of asphalt mixes is shown in Table 3 . The results indicated that AC14-75 and A20-75 blow property of asphalt mix had low percentage of binder content of $4.7 \%$ and $4.3 \%$ in the given order. This showed that AC14-75 and AC20-75 blow asphalt mixes might have increased the frictional contact between aggregate particle and the overall stiffness and stability of the asphalt mixes as compared to other asphalt mixes. However, SMA750, AC7.50 and AC14-50 blow asphalt mixes had high percentage of binder content. This showed that increase in binder content reduce the frictional contract between aggregate particles. Beyond a certain value, further increases in binder content reduce the frictional contact between aggregate particles and the overall stiffness and stability of the asphalt [19]. At low percentages, added binder content increases the mix cohesion and strength [38]..

Average Marshall Compaction stability and Marshall Compaction flow for different types of asphalt mixes are shown in Table 4. As it can be seen from the analyses, AC20-70 blow asphalt mix had high stability of $16 \mathrm{kN}$ as compared to other asphalt mixes. AC7-50, AC14-50 and AC14-75 blow asphalt mix had a similar strength and stability of $15.1 \mathrm{kN}$. This indicated that the asphalt mixes pavement will have the necessary bearing capacity to support the expected traffic loads and durability to withstand weathering. Marshall Compaction flow rate for AC20-75 blow was less as compared to other asphalt mixes. However, SMA7-50 blow had poor strength and stability and high Marshall Compaction flow of $5.3 \mathrm{~mm}$, and can highly affect the pavement performance. Recent laboratory studies have shown that the compaction can highly affect the performance of the hot-mix asphalt mixtures [30, 31].

Average air voids contents for different types of asphalt mixes, and mass that are needed for the specimens in order to get $5 \%$ and $8 \%$ air voids to each mixture are shown in Figure 4 to Figure 8. From the data it has been demonstrated AC20-75 asphalt mix (Figure 8) had superior in pavement performance. This shows that the content of a mix is more stable and durable of asphalt pavement. AC7-50 (Figure 5) and AC14-75 (Figure 7) blow asphalt mixes had shown increased in air void content above the limit. Linden and Van Der Heiden [39] described that every $1 \%$ increase in voids above $7 \%$, there would be a reduction in pavement life of about $10 \%$ or that the pavement life would be reduced by about 1 year. However, SMA7-50 blow (Figure 4) and AC14-50 blow (Figure 6) has poor performance with less than $2 \%$ air voids. This shows that the asphalt mixes might be exposed to flushing and rutting of asphalt pavement. Austroad [19] stated that air voids should not too low (less than 2 or 3\%) because plastic flow may occur resulting in flushing, bleeding, shaving or rutting of pavement. Similarly, Aggregate particles that are into close contact are able to resist load with lower strain and hence are stiffer.

\section{Conclusions}

The pavement materials performance for strength and durability of hot mix asphalt mixes using the engineering characterization and variability for asphalt mixes parameters such tensile strength ratio, resilient modulus, wheel tracking, asphalt binder content and Marshall compaction tests in a laboratory experiment for different types of asphalt mixes was assessed. 
The comparison of the different types of asphalt mixes using a standard tests methods and techniques revealed that an AC20-75 Blow asphalt mix method is the most efficient and effective in all categories of engineering characterization and variability of asphalt performance measures for strength and durability of HMA than SMA7-50, AC7-50, AC14-50, and AC14-75 blow asphalt mix. AC14-75 blow asphalt mix was the second best that increases the frictional contact between aggregate particles and overall stiffness and stability of the asphalt mix.

For a mix design purposed, all the asphalt mixes that are used in this study can strength and stable the stiffness of pavement that is notable, and the modification effect rank can be described as AC2075 Blow > AC14-75 Blow > AC14-50 Blow > AC7-50 Blow > SMA7-50 Blow in this research.

Table 2: Tensile Strength (Dry and Moisture) for Different Types of Asphalt Mixes

\begin{tabular}{|c|c|c|c|c|}
\hline \multicolumn{5}{|c|}{ Moisture Sensitivity } \\
\hline \multirow{2}{*}{ Rank } & \multicolumn{2}{|c|}{ Tensile Strength (kPa) } & \multirow{2}{*}{ TSR (\%) } \\
\cline { 2 - 4 } & & Dry & Moisture & \\
\hline $\mathbf{3}$ & SMA7 - 50 Blow & 686.9 & 626.6 & 91.2 \\
\hline $\mathbf{1}$ & AC7 - 50 Blow & 831.5 & 938.7 & 112.9 \\
\hline $\mathbf{4}$ & AC14 - 50 Blow & 990.4 & 894.8 & 90.3 \\
\hline $\mathbf{5}$ & AC14 - 75 Blow & 1225.5 & 995.7 & 81.2 \\
\hline $\mathbf{2}$ & AC20 - 75 Blow & 995.4 & 1024.8 & 103 \\
\hline
\end{tabular}

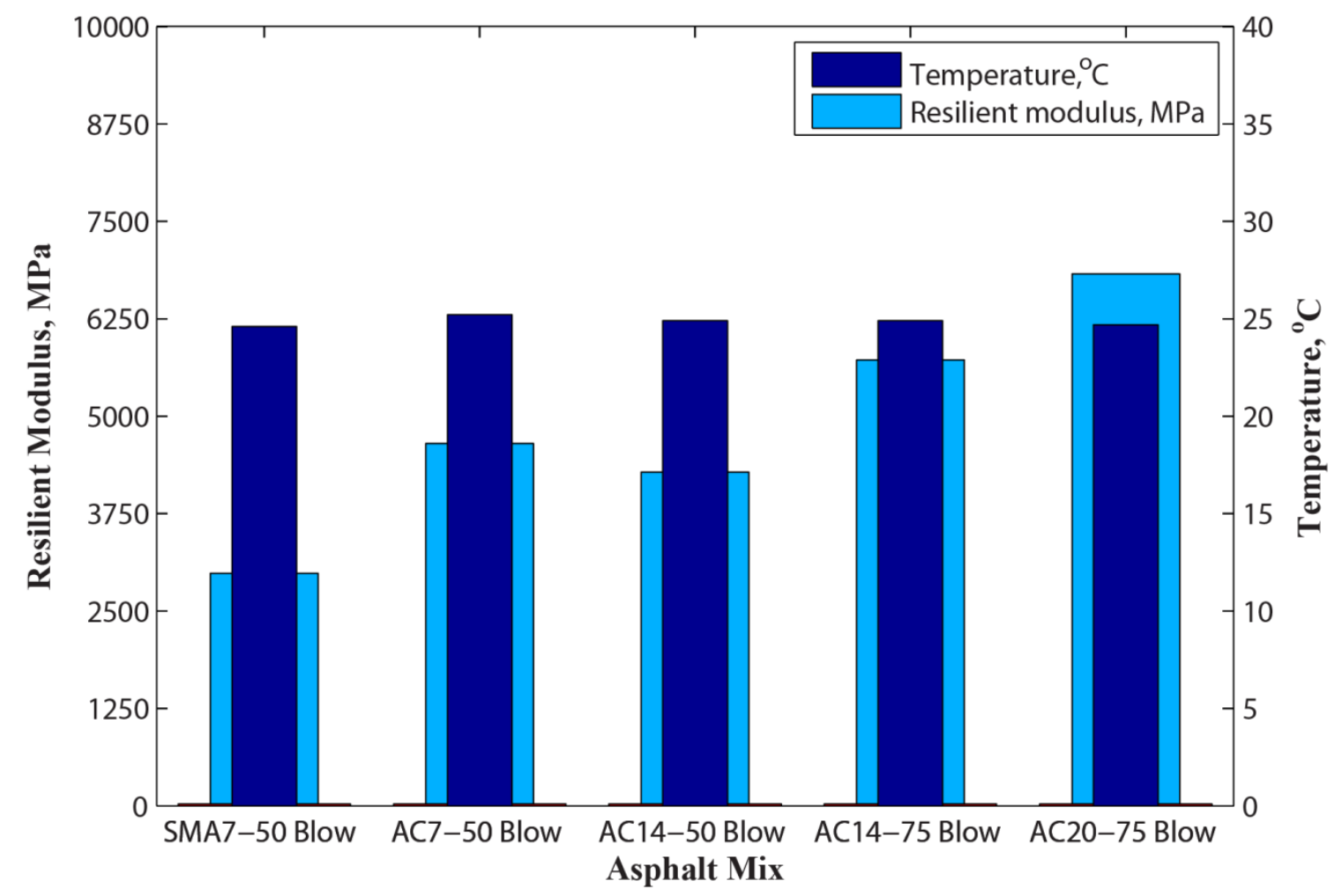

Figure 1: Resilient Modulus (MPa) and Temperature $\left({ }^{\circ} \mathrm{C}\right)$ of Different Types of Asphalt Mixes 


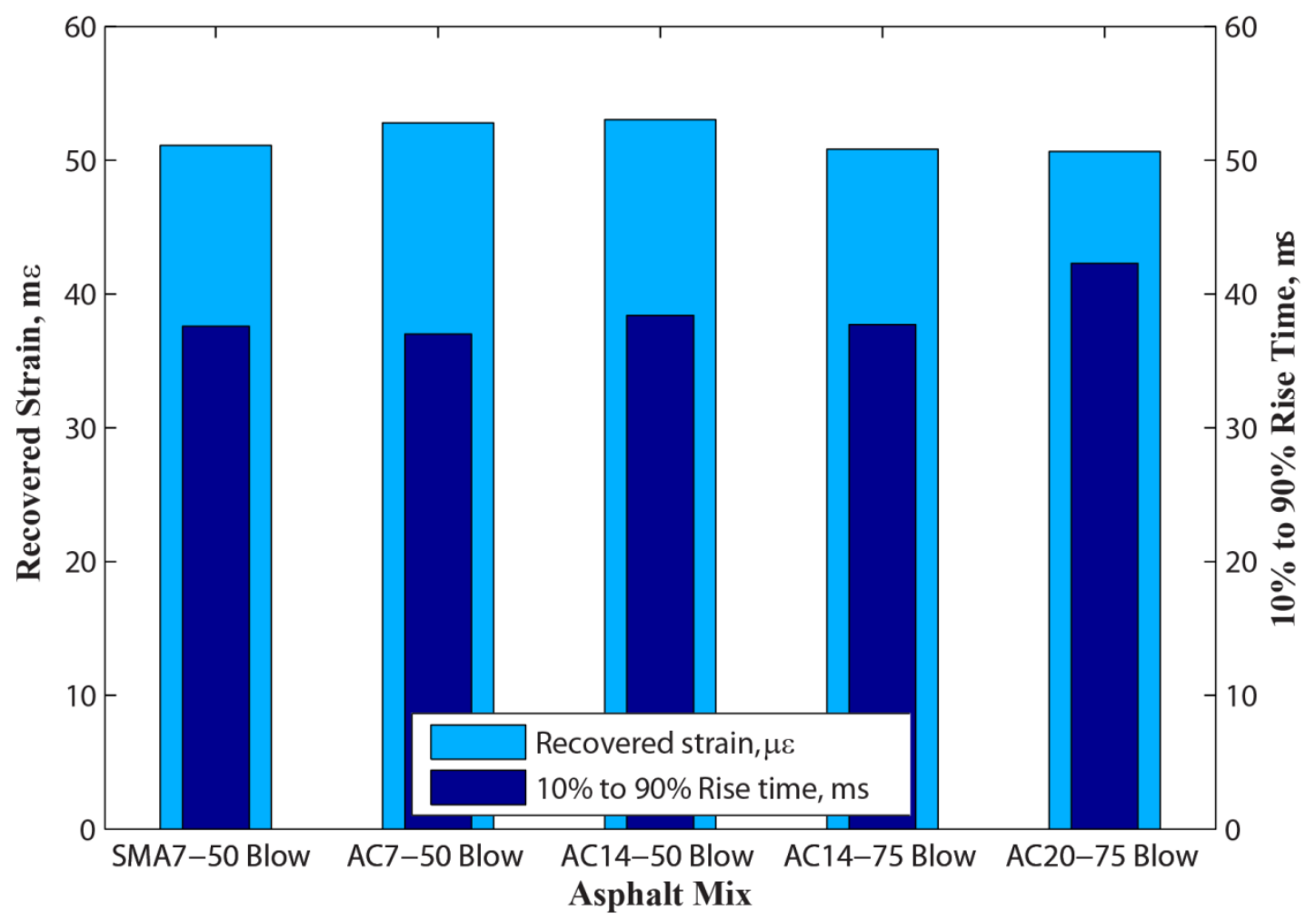

Figure 2: Recovered strain $(\mu \varepsilon)$ and $10 \%$ to $90 \%$ Rise time (ms) for Different Types of Asphalt Mixes

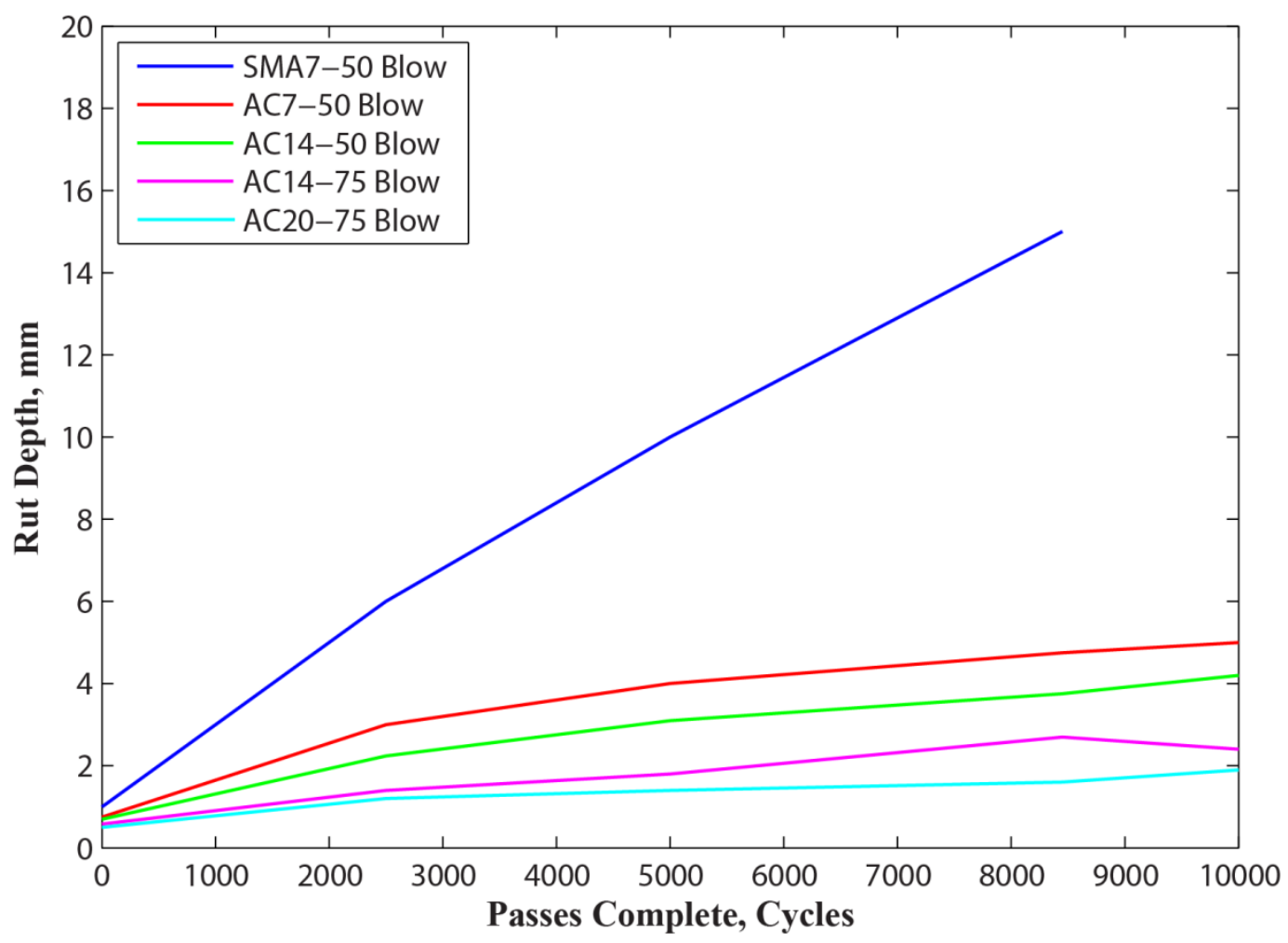

Figure 3: Average wheel tracking tests for different types of asphalt mixes 
Table 3: Asphalt binder content for different types of asphalt mixes

\begin{tabular}{|c|c|c|}
\hline \multicolumn{3}{|c|}{ Asphalt Binder Contents } \\
\hline Rank & Mix & Binder content (\%) \\
\hline $\mathbf{5}$ & SMA7-50 Blow & 6.7 \\
\hline $\mathbf{4}$ & AC7-50 Blow & 6.3 \\
\hline $\mathbf{1}$ & AC14-50 Blow & 5.3 \\
\hline $\mathbf{3}$ & AC14-75 Blow & 4.7 \\
\hline $\mathbf{2}$ & AC20-75 Blow & 4.3 \\
\hline
\end{tabular}

Table 4: Average Marshall Stability and flow of different types of asphalt mixes

\begin{tabular}{|c|c|c|c|}
\hline \multicolumn{4}{|c|}{ Marshall Stability and Flow } \\
\hline Rank & Mix & Stability (kN) & Flow (mm) \\
\hline $\mathbf{5}$ & SMA7-50 Blow & 10.1 & 5.3 \\
\hline $\mathbf{4}$ & AC7-50 Blow & 15.1 & 4.3 \\
\hline $\mathbf{1}$ & AC14-50 Blow & 18.0 & 3.8 \\
\hline $\mathbf{3}$ & AC14-75 Blow & 15.1 & 3.8 \\
\hline $\mathbf{2}$ & AC20-75 Blow & 16.0 & 3.5 \\
\hline
\end{tabular}

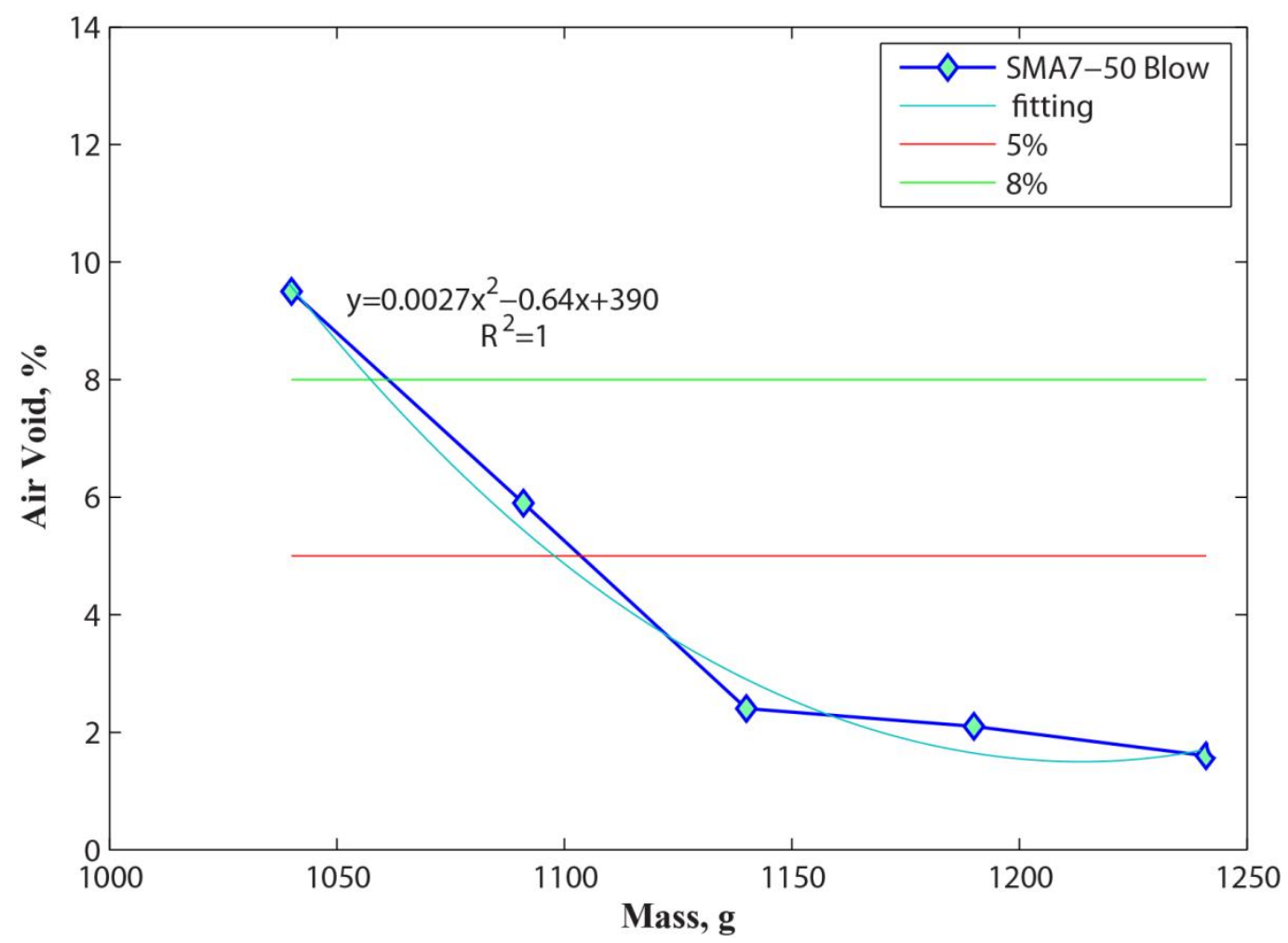

Figure 4: Mass versus air voids weight for SMA7-50 Blow asphalt mix 


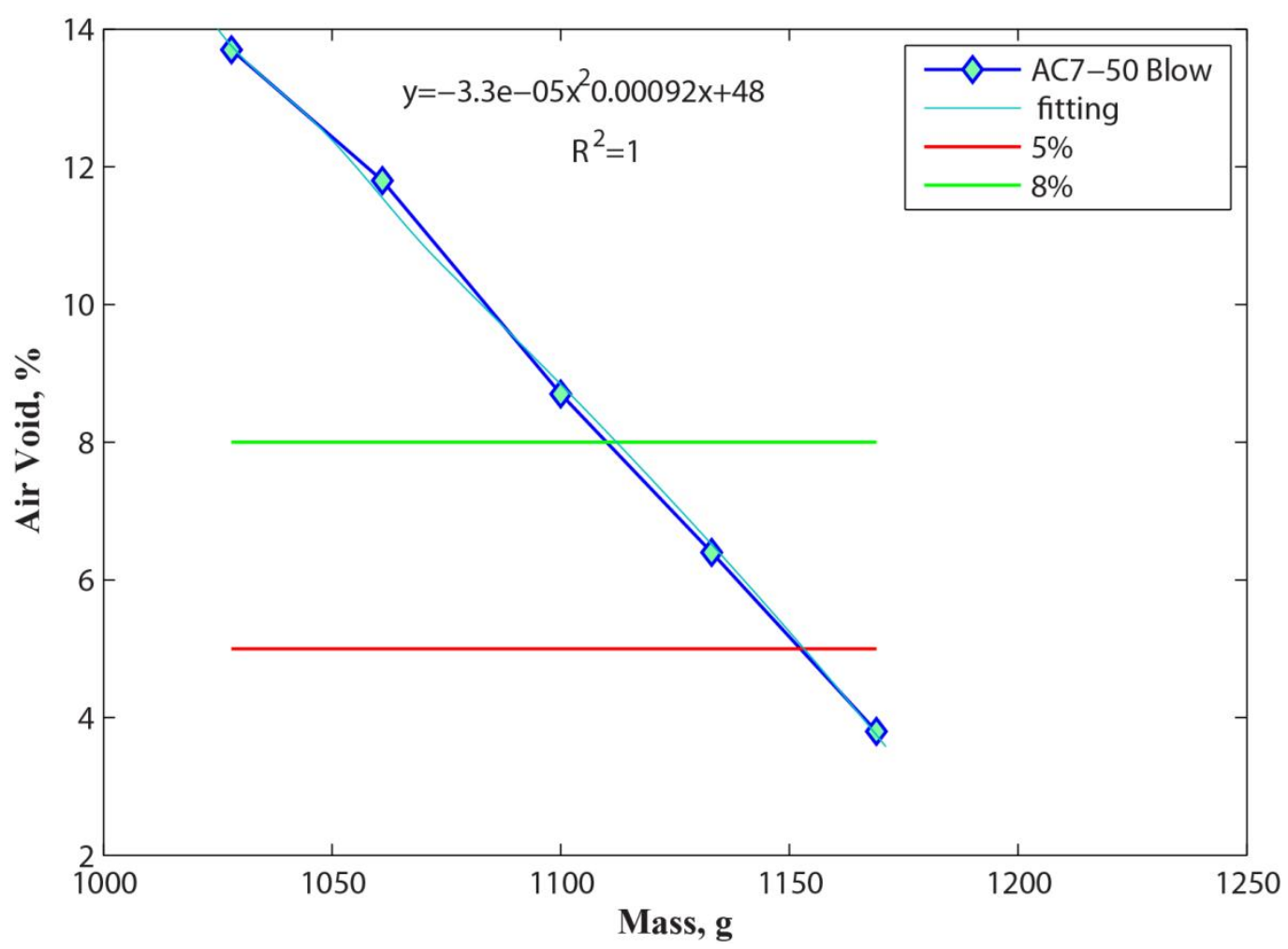

Figure 5: Mass versus air voids weights for AC7-50 Blow asphalt mix

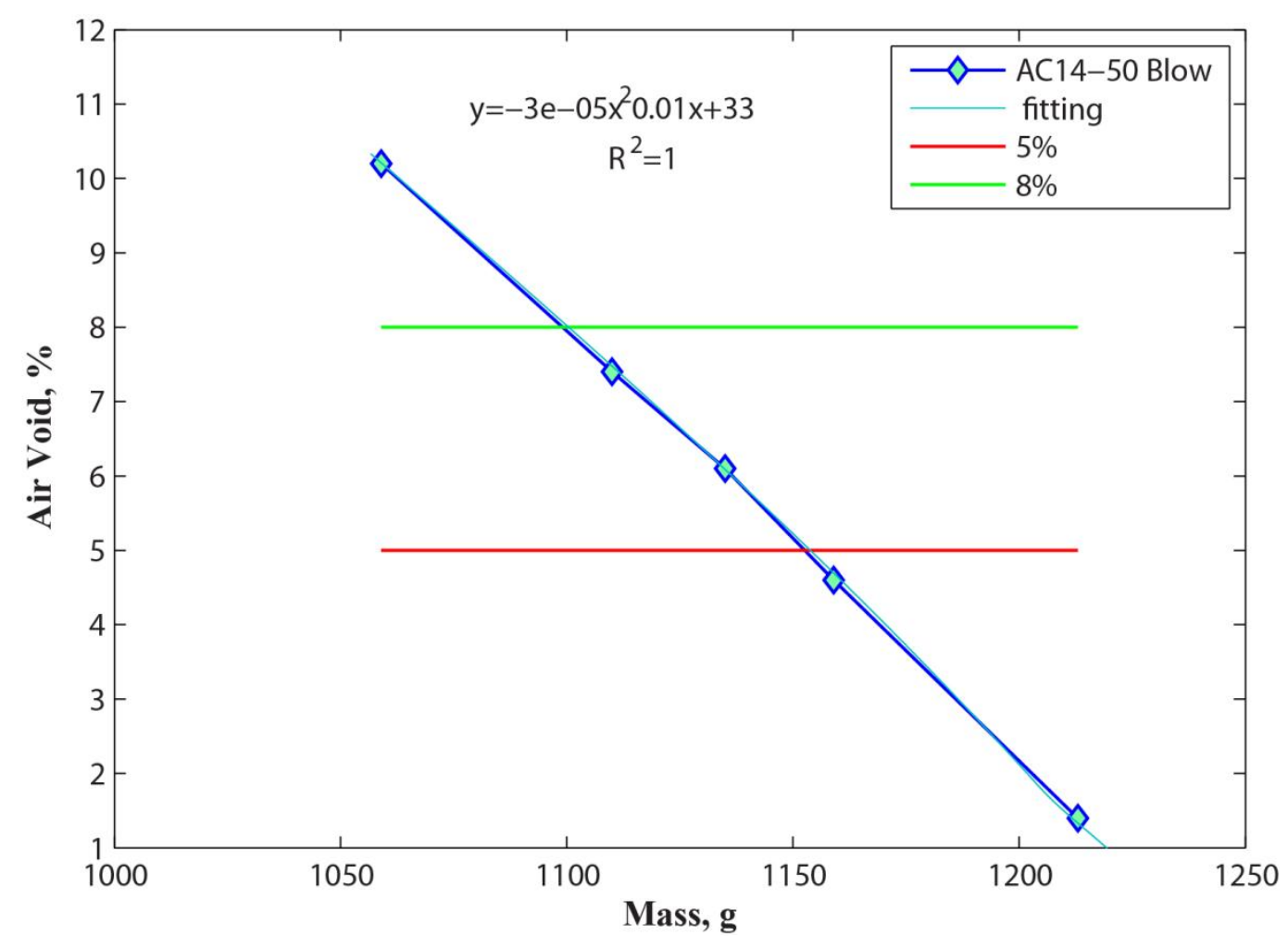

Figure 6: Mass versus air voids weights for AC14-50 Blow asphalt mix 


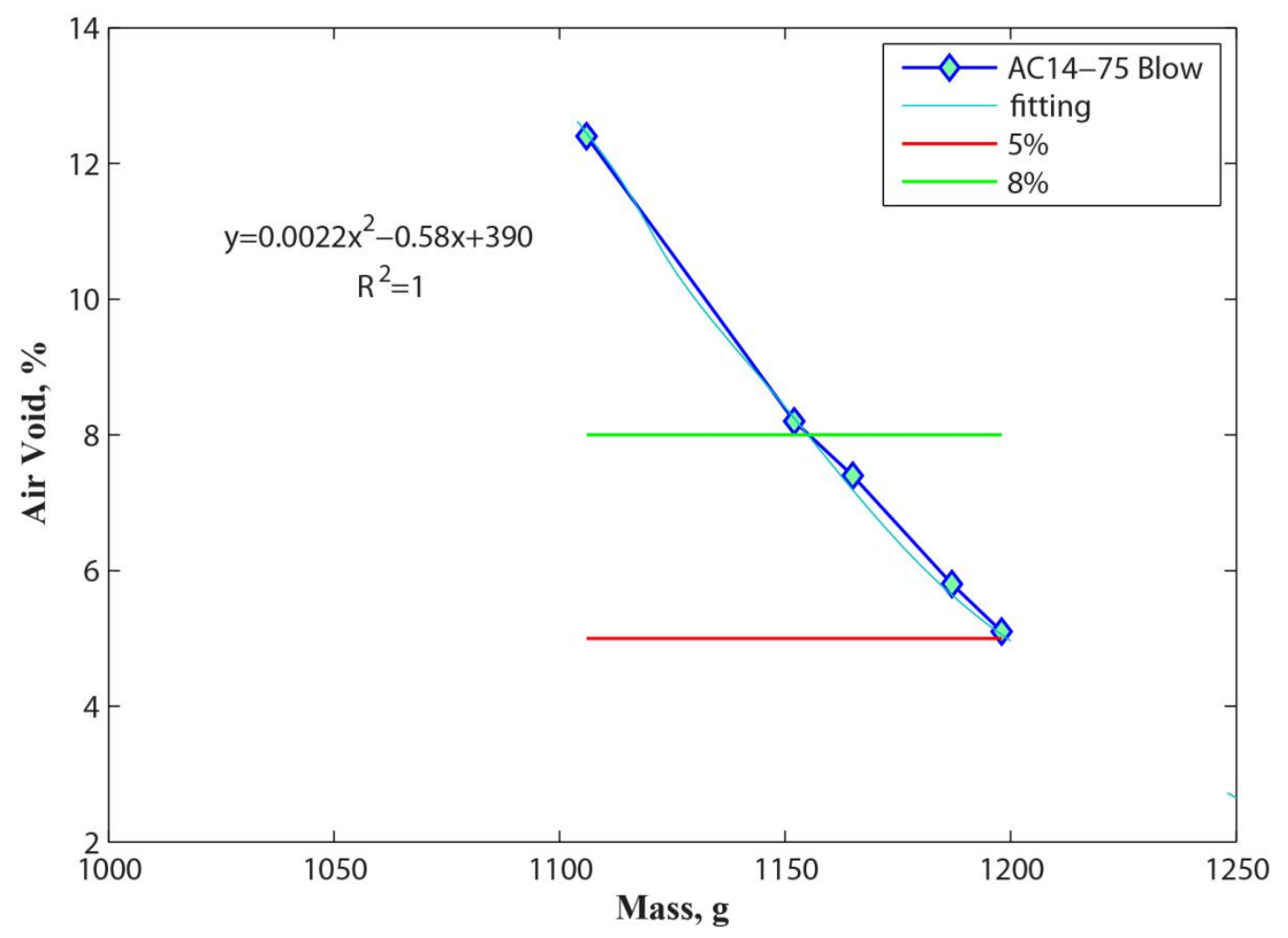

Figure 7: Mass versus air voids weight for AC14-75 Blow asphalt mix

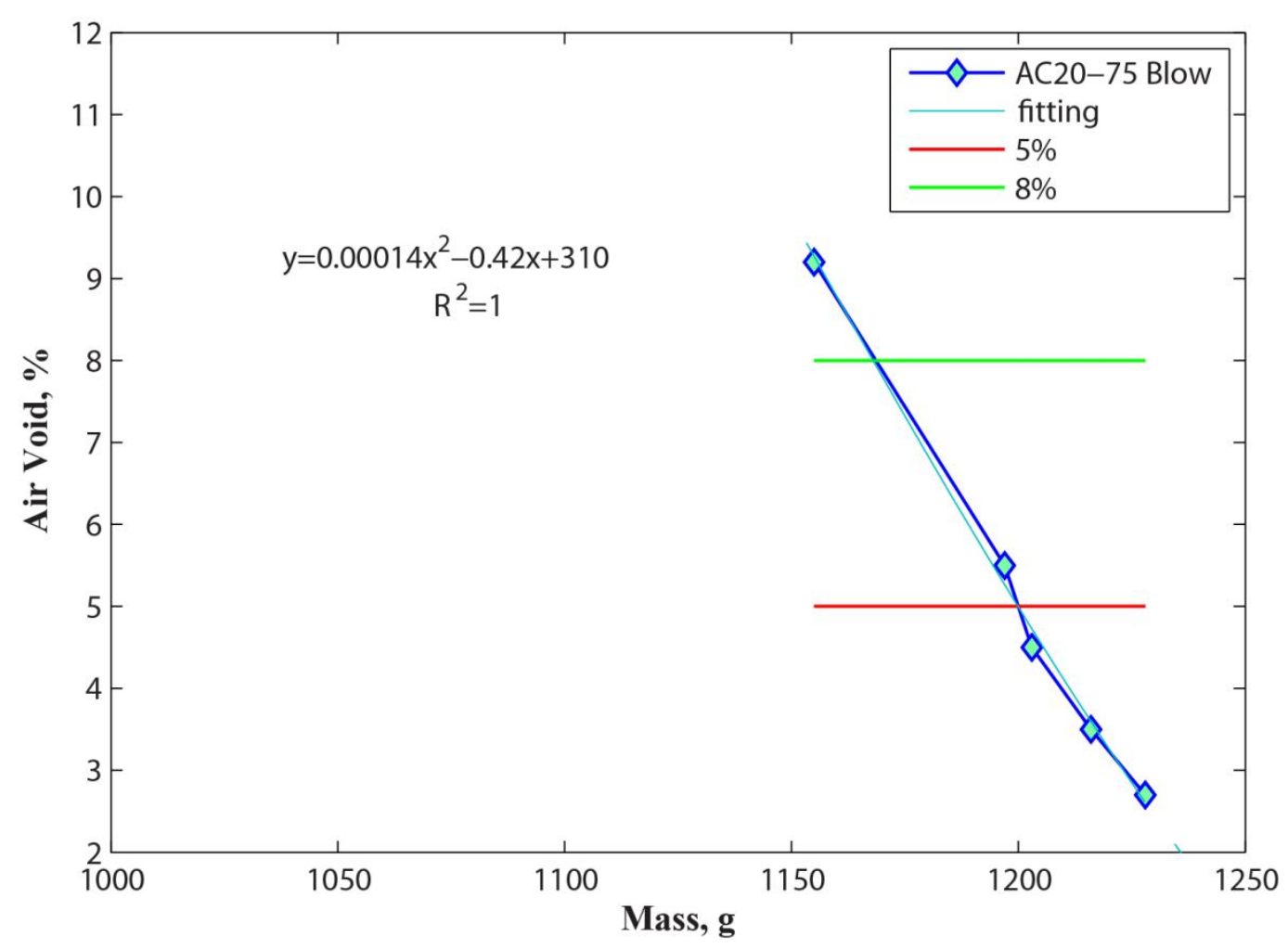

Figure 8: Mass versus air voids weight for AC20-75 Blow asphalt mix

\section{Acknowledgement}

The financial support for this study was provided by the research project 2011/0006, entitled "Characteristics of Western Australia Asphalt Mixes" sponsored by Australia Postgraduate Awards (APA), Curtin Research Scholarship (CRS) and the Mainroads Western Australia. 
The options, findings and conclusions expressed in this publication are not necessary those of Australia Postgraduate Awards, Curtin Research Scholarship or Mainroads Western Australia.

\section{References}

[1] B.A. Chadbourn, J.A. Luoma, D.E. Newcomb, V.R. Voller, Consideration of hot-mix asphalt thermal properties during compaction, in: D.S. Decker (Ed.) Quality management of hot-mix asphalt, ASTM STP 1299, American Society for Testing and Materials, Minneapolis, Minnesota, 1996, pp. 127-135.

[2] H.M. Gillespie, A century of progress: the history of hot mix asphalt, National Asphalt Pavement Association, Nanham, MD, USA, 1992.

[3] T.D. Gillespie, S.M. Karamihas, D. Cebon, M.W. Sayers, M.A. Nasim, W. Hansen, N. Ehsan, Effects of heavy vehicle characteristics on pavement response and performance, in, Transportation Research Institue, The University of Michigan, Michigan, USA, 1992.

[4] American Concrete Institute Committee, Aggregates for concrete, in: W.R. Malisch (Ed.) Materials for concrete construction, American Concrete Institute, Farmington Hills, MI, USA, 2007, pp. E1-99.

[5] Cement Concrete \& Aggregates Australia, Report on concrete pavement maintenance / repair, in, Cement Concrete \& Aggregates Australia, Australia, 2009, pp. 1-15.

[6] D.M. Mrawira, J. Luca, Effect of aggregate type, gradation, and compaction level on thermal properties of hot-mix asphalts, Canadian Journal of Civil Engineering, 33 (2006) 1410-1417.

[7] C.C. Yang, R. Huang, W. Yeih, I.C. Sue, Aggregate effect on elastic moduli of cement-based composite materials, Journal of Marine Science and Technology, 3 (1995) 5-10.

[8] C.C. Yang, Y.Y. Lin, R. Huang, Elastic modulus of concrete affected by elastic moduli of mortar and artificial aggregate, Journal of Marine Science and Technology, 4 (1996) 43-48.

[9] American Association of State Highway and Transportation Officials, Resistance of compacted bituminous mixture to misture induced damage, in: Standard Specifications for Transportation Materials and Methods of Sampling and Testing, AASHTO T283, Washington, D.C, 1986.

[10] A.J. Hoiberg, Bituminous materials: asphalts, tars and pitches, John Wiley and Sons, New York, 1964.

[11] A.J. Hoiberg, Bituminous materials: asphalts, tars and pitches, in, R.E. Krieger Pub. Co., New York, 1979, pp. 604.

[12] J. Uzan, Characterization of asphalt concrete materials for permanent deformation, International Journal of Pavement Engineering, 4 (2003) 77-86.

[13] Y. Yildirim, Polymer modified asphalt binders, Construction and Building Materials, 21 (2007) 66-72.

[14] K. Gopalakrishnan, S. Kim, Support vector machines approach to HMA stiffness prediction, Journal of Engineering Mechanics, 137 (2011) 138-146.

[15] Y.B. Dibike, S. Velickov, D. Solomatine, M.B. Abbott, Model induction with support vector machines: introduction and applications, Journal of Computing in Civil Engineering, 15 (2001) 208216.

[16] E.R. Brown, P.S. Kandhal, J. Zhang, Performance testing for hot-mix asphalt, in: C. Cullather, J. Correro, J. Weeks, J. Awan (Eds.) Transportation Research Circular E-C068: New Simple Performance Tests for Asphalt Mixes, Transportation Research Board, Washington, DC, 2004, pp. 85-106.

[17] Main Roads Western Australia, Annual Report, in, Main Road Western Australia, Perth, WA, Australia, 2007, pp. 1-134.

[18] Austroads, A guide to the structureal design of road pavements: pavement materials, Austroads, Sydney, Australia, 1992.

[19] Austroads, Asphalt characterization of pavement design, in, Austroads, Sydney, Australia, 2006, pp. 1-47.

[20] Austroads, Testing asphalt in accordance with the Austroads mix design procedures, in: A. Alderson (Ed.), Austroads, Sydney, Australia. , 2008, pp. 1-71. 
[21] S.G. Jahromi, A. Khodaii, Comparing factors aftecting resilient modulus in asphalt mixtures, Transaction A: Civil Engineering, 16 (2009) 367-375.

[22] Y.H. Huang, Pavement analysis and design, 2nd ed., Prentice Hall Inc., New Jersey, USA, 1993.

[23] R.P. Elliott, S.I. Thornton, Resilient modulus and AASHTO pavement design, in: Transportation Research Record No.1196, Pavement Evaluation and Rehabilitation, Transportation Research Board, Washington, DC, 1988, pp. 116-124.

[24] J.W.H. Olive, A.J. Alderson, The effect of air void content on resilient modulus, dynamic creep and wheel tracking results, in, ARRB Transport Research Ltd, Australia, 1995a.

[25] J.T. Harvey, J.A. Deacon, B.W. Tsai, C.L. Monismith, Fatigue performance of asphalt concrete mixes and its relationship to asphalt concerte pavement performance in California, in, University of California Berkeley, Calfornia, USA, 1995.

[26] S.F. Said, Variability in roadbase layer properties conducting indirect tensile test, in: Proceedings of the 8th International Conference on Asphalt Pavements, Seattle, Washington, DC, 1997, pp. 977-986.

[27] Strategic Highway Research Program, Fatigue response of asphalt - aggregate mixes, SHRP A 404, Strategic Highway Research Program, Washington, D.C, 1994b.

[28] L.E. Santucci, Thickness design procedure for asphalt and emulsified asphalt in: Proceedings of the 4th International Conference on Structural Design of Asphalt Pavements, Ann Arbor, Michigan, USA, 1977, pp. 424-456.

[29] Z.A. Khan, H.I. Al-Abdul Wahab, I. Asi, R. Ramadhan, Comparative study of asphalt concrete laboratory compaction methods to simulate field compaction, Construction and Building Materials, 12 (1998) 373-384.

[30] R.N. Linden, J.P. Mahoney, N.C. Jackson, Effect of compaction on asphalt concrete performance, in: Transportation Research Record No. 1217, Transportation Researh Board, National Research Council, Washington, DC, 1992, pp. 20-28.

[31] M.S. Pourtahmasb, M.R. Karim, Evaluation of the laboratory compaction effect on stone mastic asphalt mixtures, in: Proceeding of Malaysian Universities Transportation Research Forum and Conference, 21 December 2010, Universiti Tenaga Nasional, Putrajaya, Malaysia 2010, pp. 411-420.

[32] B. Choubane, G.C. Page, J.A. Musselman, Investigation of water permeability of coarse graded superpave pavements, Journal of Association Asphalt Paving Technologists, 67 (1998) 254-276.

[33] G.D. Airey, A.E. Hunter, A.C. Collop, The effect of asphalt mixture gradation and compaction energy on aggregate degradation, Construction and Building Materials, 22 (2008) 972-980.

[34] American Association of State Highway and Transportation Officials, Resistance of compacted bituminous mixture to moisture induced damage, in, Washington, DC, USA, 2000.

[35] A.K. Apeagyei, W.G. Buttlar, B.Y. Dempsey, Moisture damage evaluation of asphalt mixtures using AASHTO T283 and DC(T) fracture test, in: 10th International Conference on Asphalt Pavement - August 12-17,2006, International Society for Asphalt Pavements, Quebec, Canada, 2006, pp. 740-751.

[36] Main roads Western Australia, Procedure for the design of flexiable pavement, in: Engineering road note 9, TRIM 05/5236, Main Road Western Australia, Perth, Western Australia, 2010, pp. 130 .

[37] G.R. Hicks, C.L. Monismith, Factor influencing the resilient response of granular materials, in: Highway Research Record 345, National Research Council, Washington, DC, 1981, pp. 15-31.

[38] R.M. Anderson, D.E. Walker, P.A. Turner, Low-Temperature Evaluation of Kentucky Performance-Graded 70-22 Asphalt Binders, Transportation Research Record: Journal of the Transportation Research Board, 1661 (1999) 69-74.

[39] F. Linden, J. Van Der Heiden, Some aspect of the compaction of asphalt mix and its influence on mix properties., in: Proceeding of the Association of Asphalt Paving Technologists, Association of Asphalt Paving Technologists, 1989, pp. 571-623. 